ON THE ARREST OF POST-PARTUM UTERINE HEMORRHAGE BY THE INJECTION OF COLD WATER IN'TO THE UTERINE CAVITY.

By CHARLES SIMPSON, M.R.C.S.E., Stamford.

I FEEL a deep interest in the recent advances in obstetrics. Just in proportion as physiology is brought to bear on midwifery so far will it be elevated from empirical art to scientific practice. Dr. Tyler Smith's minute, careful, and explanatory record of the cases of uterine hamorrhage, in THE LANCET, (July 7 th and Dec.29th, vol. ii. 1849,) places the injection of cold water into the uterine cavity, in hæmorrhage after delirery, on a rational footing. I have had one opportunity of testing the utility and safety of this plan of treatment. I injected, at intervals, and within an hour, upwards of a gallon of water. Its influence in subduing the hæmorrhage was decisive, nor was it followed by any untoward symptom. The case was one of extreme character; there seemed no hope of recovery; it was the formidable case recorded in The LANCET, (May 20th, vol. i. 1848,) wherein $I$ induced and kept up gentle and effective respiration, by repeatedly, at measured intervals, blowing on the face; and, also, wherein I excited deglutition by dashing cold water on the face, the mouth being previously filled with stimulant. I omitted, at the time, to record the injection of cold water into the cavity of the uterus, for two reasons: first, I was desirous of keeping the record of the case clear of everything but the treatment of the effects of uterine hæmorrhage; and secondly, I felt that the publication of such apparently violent treatment would scarcely have been justified, without mature reflection and physiological explanation, (which Dr. Smith has given,) notwithstanding the happy and harmless result of its application.

Stamford, Jan. 1850.

\section{ON AN INSTANCE OF IMPERVIOUS RECTUM IN A NEWLY-BORN INFANT, SUCCESSFULLY TREATED BY OPERATION.}

BY JOHN PICKOP, M.R.C.S.E., \&c., Blackburn.

As it is the exception for nature to produce a matured ovum, requiring the immediate interference of surgery to enable it to discharge the various functions necessary to life, perhaps the following report may be deemed worthy of a place in The Lancet.

On the 13th of July I attended Mrs. M- in labour of her first child, a female. During my visit, the following day, I was informed that the child's bowels had not been moved, but, hoping they might be during the day, I took little notice of the remark.

July 15th.-The bowels still unmoved, though castor oil had been given. The child would not take the breast, and vomited any fluid almost as soon as taken. Bowels much distended. Retching, hiccough, and other symptoms of severe enteritis. Ordered a calomel powder immediately, and a teaspoonful, every three hours, of a mixture, containing a saline laxative, with tinctures of cardamoms and henbane.

16th.-Vomiting abated. Belly still as usual, without any evacuation. I proceeded to inject a little warm water per anum, but was surprised to find it instan tly returned, unaltered. This induced me to introduce my finger, as I imagined there might exist some imperfection in the passage. On doing so, I found, that when my finger had passed about an inch and a half, the bowel was closed, precisely like the end of the finger of a glove. I could not detect any distended portion of bowel to correspond. This condition of parts fully disclosed the nature of the case. I explained to the mother the immediate necessity of an operation, to afford the child any chance of life, to which she consented.

17 th.-In the presence, and with the advice, of Mr. Grime, surgeon, and Dr. Irvine, I introduced a sharp-pointed bistoury, against my finger, to the seat of obsfruction, and pushed it on about an inch. On withdrawing, nothing escaped but a little venous blood. I then passed through the opening a small bougie, on which being removed, there followed a copious discharge of meconium, and other matter. From this time the child became easier, and on the following day began to take the breast. The mixture was continued for a few days, and also the introduction of the bougie. The bowels are regularly moved, and the child is in perfect health.

The removed extremities of the rectum appeared to be connected by a short band of fibrous membrane. I have before seen cases of imperforate anus, but not of impervious rectum. Blackburn, Angust, 1819 .

\section{SINGULAR CONGENITAL MALFORMATION.} To the Editor of The LANCET.

SIR,-Having for many years been a reader of your valuable journal, I take the liberty of sending to you a statement of a case which occurred in my practice, in November, 1825 , and if you think it worth publishing, you will give it a place in your columns. On the 21 st of November, 1825 , I was called on, in the evening, to visit $E . G-$ a married woman, aged forty-seven, living about four miles from my residence. She was the mother of eight children, but only reared four of them; they were all perfectly formed, and were born previously to the accident the father met with, and which $I$ am about to mention. When I arrived she had two midwives with her, who told me she had been in labour two days and nights, and that the pains had ceased for many hours; she was much exhausted, had a weak pulse, but no flooding, nor had there been any; it was a breech presentation. I gave her stimulants, and tried the usual means to reproduce pains, but without effect. I was not, at that time, acquainted with the use of the ergot of rye, and if I had been, I think, in this case, it would have proved useless. This is a short, muscular woman, with rather a roomy pelvis; but the size of the child was immense. After waiting some time, I delivered her with the blunt hook, but not without some difficulty, when, to my astonishment, the child's right upper arm was only a stump, appearing exactly like an arm should be after a good amputation; the right eye was also wanting. The mother recovered, and is still living. The father of the child was a sailor, wounded in the arm by a ball, and had his eye knocked out by a splinter of wood: My reason for sending this to you is, that soon after this case occurred, I read in some journal the opinion of a physician, that the progeny of a person maimed by accident never partakes of the deformity. The eye wanting, and the stump, were, like the father's, on the right side.

I am, Sir, yours obediently,

Modbury, Devon, 1850. WM. S. Langworthy, M.R.C.S.E., \&c.

\section{ON THE \\ FUNCTIONS AND USES OF THE THYMUS GLAND. \\ To the Editor of The LanceT.}

Sir,-The thymus gland has ever been a favourite battleground for theoretical opinion, with regard to the date of its discovery, the derivation of its name, its anatomy, and, lastly, its function and uses. The first two are of little import: its anatomy Sir A. Cooper fully elucidated; but its function and uses still remain debatable ground. On these points (and the latter especially) I beg to suggest the following groundwork for an application of the knowledge with which anatomy has furnished us. Should it be found worthy, its adoption may form the basis for more detailed investigations if found wanting, it must, at least, be acknowledged, primô facie, to be more worthy of credit than the views promulgated by Wharton, Martineau, Collins, and a host of other theorists. I remain, Sir, yours obediently,

\section{University College. Theory.}

1. At the period of evolution of the human fotus, the upper portion of the body is developed to a very considerably greater extent than the lower, as during intra-uterine life, the former alone is required for the purposes of existence.

2. After birth these hypo-developed portions of the frameviz., lower extremities, take on a rapid genesis to bring them to the comparative standard required for the fulfilment of their presently-to-be-allotted duties; this period of increase, during which they grow with greater rapidity than the rest of the body, extending over the first two years of mundane life.

3. The source of production of added portions of the human frame, from its earliest intra-uterine cellular genesis, is corpuscular-a strong hypothesis hence arises that the corpuscular portion of the fluid which supplies animal pabulum for conversion is the source of elaboration into new definite existence.

4. The increase of the lower extremities (referred to in $\$ 2$ ) goes on with greater rapidity than any other considerable portion of the body at any one period of life; hence the amount of convertible material required must be proportionally large; whereas, no organ has yet been demonstrated as specially endowed with the power of supplying this arge 